\title{
The confused patient in the acute hospital
}

\author{
The Hot Topic Symposium on The Confused Patient in the Acute Hospital was held on 7 September 2012 at \\ The Royal College of Physicians of Edinburgh
}

F Doubal

Clinical Lecturer, Geriatric Medicine, Department of Geriatric Medicine, University of Edinburgh, Royal Infirmary of Edinburgh, UK

DECLARATION OF INTERESTS No conflicts of interest declared.

\author{
Correspondence to F Doubal, \\ Department of Geriatric Medicine, \\ University of Edinburgh, \\ Royal Infirmary of Edinburgh, \\ 5 I Little France Crescent, \\ Edinburgh EHI6 4SB, UK \\ tel. +44 (0) I 3 I 242648 I \\ e-mail fergus.doubal@ed.ac.uk
}

\section{INTRODUCTION}

Over half of older adults admitted to hospital are confused.' This may be due to pre-existing dementia, a learning disability or an acute episode of confusion (delirium). All of these conditions can be distressing for the patient and their family. They can lead to increased morbidity and mortality. Confusion needs to be recognised early and treated appropriately. This timely symposium provided healthcare workers of all disciplines with the knowledge and skills to improve the detection, treatment and quality of care of those with dementia, learning disability and delirium.

\section{SESSION I - ASSESSMENT: CLARIFYING THE TYPE AND CAUSE OF CONFUSION}

Dr Stephen Potts (Consultant Liaison Psychiatrist, Royal Infirmary of Edinburgh) advised that discharging a confused patient from hospital (especially from the emergency department) is difficult, reflecting high case complexity and often associated frailty. It requires a careful assessment of risks and benefits in full consultation with the carer/ family and primary care team. Anticipatory care planning for frail patients greatly facilitates decision-making at the point of access to emergency care.

Dr Andrew Farrall (Consultant Neuroradiologist, Western General Hospital, Edinburgh) showed that brain imaging (computed tomography) detects acute abnormalities (e.g. subdural haemorrhage, acute stroke, brain tumour) in $8-14 \%$ of patients diagnosed with delirium. ${ }^{2}$ According to the British Geriatrics Society Guidelines, brain scanning is indicated in delirious patients with focal neurological deficits, in those who have had a fall, suffered a head injury and in those with signs of increased intracranial pressure. ${ }^{3}$ Others also advocate scanning in patients taking anticoagulant treatment to identify intracranial haemorrhage. Scanning in patients not in these categories is very unlikely to be informative and carries disadvantages (further disorientation for the patient, potential delay in giving other treatments and cost).
Professor Emma Reynish (Consultant Geriatrician,Victoria Hospital, Kirkcaldy) stated that $40 \%$ of patients over 70 years old admitted to hospital had dementia but that this condition had been previously diagnosed in less than $50 \%$ of cases. ${ }^{4}$ These undiagnosed patients often do not receive dementia-specific care either in hospital or following discharge. The assessment of patients with possible dementia during acute medical admissions (using validated tools accompanied by comprehensive geriatric assessment) provides a good opportunity to diagnose the condition and start memory treatments early, while also providing support for patients and carers.

\section{SESSION 2 - DRUGS AND ALCOHOL}

Professor Peter Passmore (Professor of Ageing and Geriatric Medicine, Queens University, Belfast) stated that drugs account for $20 \%$ of cases of delirium. ${ }^{5}$ This can be due to starting new drugs or even because of small dose changes in existing medication. Careful assessment of all medications, taking particular note of renal function (which reduces with age) is crucial to reduce the burden of drug side-effects. Non-pharmacological measures should be the first-line therapy in the treatment of the acutely disturbed patient but if this fails, careful use of small doses of antipsychotics may be considered, with a clear review date and plan for cessation.

Dr Peter Rice (Consultant Addictions Psychiatrist and Director, Tayside Alcohol Problems Service) advised that acute thiamine deficiency (often associated with alcohol intake) is a common, treatable cause of confusion in younger patients. It often presents insidiously and requires a high index of suspicion to identify and treat. Though Wernicke's encephalopathy is still seen clinically, Korsakoff's syndrome in its classical pure amnesic form is rare. Instead, a more heterogeneous spectrum of chronic alcohol-related brain damage is seen, including a large number of patients with frank dementia reflecting both the neurological sequelae of thiamine deficiency and the direct neurotoxic effects of alcohol. 


\section{SESSION 3 - LEGAL AND ETHICAL ISSUES: BEST PRACTICE}

Dr Donald Lyons (Chief Executive, Mental Welfare Commission for Scotland) delivered the Sidney Watson Smith Lecture. Clear documentation of decision-making processes ensures that any treatment occurs according to the relevant legislation, and is essential for the safe and appropriate management of patients with confusion during the acute hospital admission. Guidance exists from professional and other bodies and doctors should ensure that they are fully aware of the legal and ethical principles of treatment.

Dr Neill Simpson (Consultant Psychiatrist in Learning Disability, Gartnavel Royal Hospital, Glasgow) suggested that the assessment of patients with learning difficulties requires clear communication skills and a multi-disciplinary approach. Patients with learning difficulties present to the acute receiving unit with a higher prevalence of epilepsy and respiratory disease compared to patients without learning difficulties.

\section{SESSION 4 - CASE PRESENTATION}

The cases presented were varied but several key messages emerged: the assessment of the confused patient is complex and we should adopt a multi-disciplinary approach to management. This therefore necessitates clear and concise communication between specialties. Strenuous efforts should be made to ascertain accurate previous medical and psychiatric history and link this with collateral information from carers/family and other involved healthcare professionals. It is of course then also vital to keep family/carers fully involved at every subsequent stage of management. Careful consideration when investigating confusion will avoid either unnecessary tests or failing to adequately identify a cause for the patient's confusion. Many issues arising during the management of the confused patient in hospital can be predicted; pre-planning using innovative techniques and specialist learning disability nurses where appropriate improves outcomes. ${ }^{6}$

\section{TAKE-HOME MESSAGE}

Confusion affects almost a third of acute hospital patients and is therefore a major issue in mainstream medicine. It is associated with high levels of distress, increased length of stay and inferior outcomes. Clinicians need to accurately and reliably detect confusion which should be followed by a rapid, structured and rigorous multi-disciplinary approach involving families and carers. This should occur within appropriate legal and ethical frameworks. Careful assessment and management can greatly improve outcomes, especially in reducing patient and carer distress and lower healthcare costs.

\section{REFERENCES}

I The Royal College of Psychiatrists. Who cares wins. Improving the outcome for older people admitted to the general hospital: guidelines for the development of liaison mental health services for older people [Internet]. London:The Royal College of Psychiatrists; 2005 [cited 2012 Sept 19]. Available from: http://www.rcpsych.ac.uk/PDF/ WhoCaresWins.pdf

2 Hufschmidt A, Shabarin V. Diagnostic yield of cerebral imaging in patients with acute confusion. Acta Neurol Scand 2008; I I 8:245-50. http://dx.doi.org/I0.1 I I I/j.1600-0404.2008.01006.x

3 British Geriatrics Society. Guidelines for the prevention, diagnosis and management of delirium in older people in hospital [Internet]. London: British Geriatrics Society; 2006 [cited 2012 Sept 19]. Available from: http://www.bgs.org.uk/index.php?option=com_con tent\&view=article\&id=|70:clinguidedeliriumtreatment\&catid=42:c atclinguidelines\&ltemid $=107$

4 Sampson EL, Blanchard MR, Jones L et al. Dementia in the acute hospital: prospective cohort study of prevalence and mortality. $\mathrm{Br}$ J Psychiatry 2009; 195:6I-6.

5 Hufschmidt A, Shabarin V, Zimmer T. Drug-induced confusional states: the usual suspects? Acta Neurol Scand 2009; 120:436-8. http://dx.doi.org/I0.I I II/j.I600-0404.2009.0I I74.x

6 Brown M, MacArthur J, McKechanie A et al. Learning disability liaising nursing services in South East Scotland: a mixed methods impact and outcome study. J Intellect Disabil Res 2012; 56:II6I-74. http://dx.doi.org/I0.IIII/j.I365-2788.20II.0I5II.x 